\title{
Downregulation of type I collagen expression in silibinin-treated human skin fibroblasts by blocking the activation of Smad2/3-dependent signaling pathways: Potential therapeutic use in the chemoprevention of keloids
}

\author{
JAE-WE CHO, KWON-JUN IL and KYU-SUK LEE
}

Department of Dermatology, Keimyung University School of Medicine, Jung-Gu, Daegu 700-712, Republic of Korea

Received December 4, 2012; Accepted February 6, 2013

DOI: $10.3892 /$ ijmm.2013.1303

\begin{abstract}
The inhibition of the Smad2/3 pathway is a key step involved in the downregulation of type I collagen synthesis, thus preventing keloid formation in tissue. In this study, we investigated the effect of silibinin on the proliferation of human skin fibroblasts (HSFs), as well as its effect on the expression of type I collagen, matrix metalloproteinase (MMP)-1, Smad2 and Smad3. Our results showed that the proliferation rates of the fibroblasts were not markedly decreased in a dose- and time-dependent manner following treatment with silibinin. Even though silibinin did not exert any cytotoxic effects on HSFs, the expression of type I collagen was markedly decreased in a dose- and time-dependent manner in the silibinin-treated HSFs. Consistent with this finding, the decreased promoter activity of type I collagen was observed in the HSFs following treatment with silibinin. The MMP-1 and MMP-2 expression levels were increased in the silibinin-treated HSFs. Moreover, the silibinin-induced downregulation of type I collagen was associated with the inhibition of $\mathrm{Smad} 2 / 3$ activation in the transforming growth factor- $\beta 1$ (TGF- $\beta 1$ )-treated HSFs. We further demonstrated that silibinin attenuated the translocation of Smad2 and Smad3 to the nucleus in the TGF- $\beta 1$-treated HSFs. Taken together, our data indicate that silibinin has the potential to prevent fibrotic skin changes by inducing the downregulation of type I collagen expression; this effect was partly mediated by the inhibition of the Smad2/3dependent signaling pathway in HSFs.
\end{abstract}

\section{Introduction}

Silibinin is a natural polyphenolic flavanoid extracted from the fruit and seeds of milk thistle (Silybum marianum). It has been reported that silibinin possesses antioxidant, anti-

Correspondence to: Dr Kyu-Suk Lee, Department of Dermatology, Keimyung University School of Medicine, 56 Dalseong-ro, DongSanDong, Jung-Gu, Daegu 700-712, Republic of Korea

E-mail: janylove99@dsmc.or.kr

Key words: type I collagen, silibinin, fibroblasts, Smad apoptotic, anti-inflammatory and anti-fibrotic properties (1-3). However, the effects of silibinin on type I collagen expression in human skin fibroblasts (HSFs) and the related signaling pathways remain unclear.

Type I collagen is a major extracellular matrix component in the dermis. It is synthesized and secreted in a soluble form by skin fibroblasts and deposited extracellularly. It is believed that transforming growth factor- $\beta 1$ (TGF- $\beta 1) / \mathrm{Smad}$ pathways play key roles in type I collagen synthesis (4-6). TGF- $\beta 1$ is known to exert a promoting effect on the extracellular matrix in a variety of cells by stimulating the synthesis of matrix proteins. An important physiological feature of TGF- $\beta 1$ includes the de novo synthesis of extracellular matrix proteins and the inhibition of the expression of matrix metalloproteinases (MMPs). Receptor-activated Smads (R-Smads; Smad2 and Smad3) are the key intracellular components in the TGF- $\beta 1$ signaling pathway involved in the production of type I collagen. Thus, the dysregulation of the TGF- $\beta 1 / \mathrm{Smad}$ pathway is crucial for the pathogenesis of hypertrophic and keloid scar formation $(7,8)$.

In this study, the anti-fibrogenic effects of silibinin were investigated by inhibiting the expression of type I collagen through the modulation of TGF- $\beta 1 / \mathrm{Smad}$ signaling pathways in HSFs.

\section{Materials and methods}

Materials. Antibodies against type I collagen, MMP-1, MMP-2, tissue inhibitor of metalloproteinase-1 (TIMP-1), Smad2 and Smad3 were obtained from Santa Cruz Biotechnology, Inc., (Santa Cruz, CA, USA). TGF- $\beta 1$ was purchased from SigmaAldrich (St. Louis, MO, USA). Smad2, Smad3, phosphorylated Smad2 (p-Smad2) and phosphorylated Smad3 (p-Smad3) were obtained from Cell Signaling Technologies (Beverly, MA, USA).

Cell culture. HSFs were maintained at $37^{\circ} \mathrm{C}$ in a humidified atmosphere of $95 \%$ air and $5 \% \mathrm{CO}_{2}$ in Dulbecco's modified Eagle's medium (DMEM) supplemented with $10 \%$ heat-inactivated FBS, $2 \mathrm{mM}$ glutamine, $100 \mathrm{U} / \mathrm{ml}$ penicillin and $100 \mu \mathrm{g} / \mathrm{ml}$ streptomycin. For the experiments, the cells $\left(5 \times 10^{4}\right.$ cells $\left./ \mathrm{ml}\right)$ were seeded in culture dishes, and maintained 
in a tissue culture incubator. The cells were treated with TGF- $\beta 1(5 \mathrm{ng} / \mathrm{ml})$ or silibinin $(0-200 \mu \mathrm{M})$ for $48 \mathrm{~h}$.

Cell counting kit-8 (CCK-8) assay. The cells were cultured in 96-well plates containing silibinin $(0-200 \mu \mathrm{M})$ with 3 replicate wells for each concentration. Following incubation for $48 \mathrm{~h}$, cell viability was measured by CCK-8 assay (Dojindo, Kumamoto, Japan), according to the manufacturer's instructions.

Western blot analysis. Whole cell extracts were prepared in lysis buffer [10 mM Tris (pH 7.4), 5 mM EDTA, $130 \mathrm{mM}$ $\mathrm{NaCl}, 1 \%$ Triton X-100, phenylmethylsulphonyl fluoride (PMSF, $10 \mu \mathrm{g} / \mathrm{ml})$, aprotinin $(10 \mu \mathrm{g} / \mathrm{ml})$, leupeptin $(10 \mu \mathrm{g} / \mathrm{ml})$, $5 \mathrm{mM}$ phenanthroline and $28 \mathrm{mM}$ benzamidine- $\mathrm{HCl}]$. The protein concentration of the extracts was estimated with Bradford reagent (Bio-Rad, Hercules, CA, USA) using bovine serum albumin as the standard. Equal amounts of protein (40 $\mu \mathrm{g} /$ lane) were resolved by $6.5-12 \%$ sodium dodecyl sulfatepolyacrylamide gel electrophoresis, and transferred onto a nitrocellulose membrane. The membrane was then washed with Tris-buffered saline (10 mM Tris, $150 \mathrm{mM} \mathrm{NaCl})$ containing $0.05 \%$ Tween-20 (TBST) and blocked in TBST containing 5\% non-fat dried milk. The membrane was further incubated with respective specific antibodies. The membrane was continuously incubated with appropriate secondary antibodies coupled to horseradish peroxidase, and blots were developed in the ECL Western blotting detection reagents (Amersham Pharmacia Biotech, Piscataway, NJ, USA).

Chloramphenicol acetyltransferase (CAT) assay. The construct containing the $3.5-\mathrm{kb}$ COL1A2 promoter fused to the CAT gene (pMS 3.5/CAT) was derived from a $3.5-\mathrm{kb}$ EcoRI/SphI genomic subclone that spans the region from position -3500 to +58 of the COL1A2 promoter. After conversion of the EcoRI site to BamHI, the eukaryotic insert was excised with BamHI and HindIII, and was subcloned into a similarly digested polylinker of the expression vector p8-CAT, a derivative of the pEMBL plasmid. Thereafter, deletion mutants were generated in the parental pUC18 subclones and subsequently transferred to the expression vector. The transfections were carried out using the calcium phosphate/DNA co-precipitation method followed by a 1-min $(15 \%)$ glycerol shock. Four hours after transfection, the cells were treated with silibinin. After a total of $48 \mathrm{~h}$ of incubation, the cells were harvested. CAT activity was determined by incubating cell extracts with $\left[{ }^{14} \mathrm{C}\right]$ chloramphenicol, followed by separation of its acetylated and non-acetylated forms by thin-layer chromatography. CAT activity in the cell extracts was calculated as radioactivity in the acetylated forms as a percentage of the total radioactivity in each sample.

Immunofluorescence analysis. To detect the intracellular localization of Smad2 and Smad3, skin fibroblasts were grown on slides in 24-well plates and then treated under the indicated conditions. After fixing with $4 \%$ paraformaldehyde for $30 \mathrm{~min}$, the cells were permeabilized and blocked with $0.1 \%$ saponin and $0.5 \%$ bovine serum albumin in phosphate-buffered saline (PBS) for $30 \mathrm{~min}$ at $4^{\circ} \mathrm{C}$. Subsequently, the samples were incubated with each primary antibody (1:50) overnight at $4^{\circ} \mathrm{C}$, then the cells were incubated with fluorescein isothiocyanate

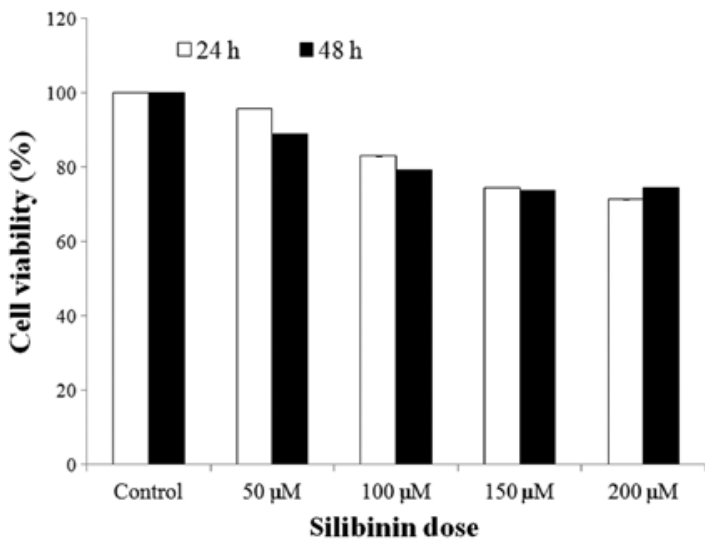

Figure 1. Non-cytotoxic effect of silibinin on human skin fibroblasts. Cells were plated at a density of $4 \times 10^{3} / \mathrm{cm}^{2}$ in 96 -well plates. Cells were cultured with or without silibinin for 2 days. Viable cells were counted using the CCK-8 assay kit. Notably, the viability of the cells was not markedly suppressed by treatment with silibinin at a concentration of $200 \mu \mathrm{M}$.

(FITC)-conjugated goat anti-rabbit IgG (1:100) for $2 \mathrm{~h}$ at room temperature. The slides were then mounted with $80 \%$ phosphoglycerol, viewed and photographed under a fluorescence microscope (Olympus, Tokyo, Japan). In a single experiment, at least 100 stained cells were analyzed per sample.

\section{Results}

Effect of silibinin on cell proliferation rates in HSFs. To determine the effect of silibinin on the proliferation rates of HSFs, cells were exposed to silibinin (0-200 $\mu \mathrm{M})$ for 2 days. As shown in Fig. 1, the proliferation rates were not markedly decreased following silibinin treatment. In addition, no cytotoxic effects of silibinin were observed in the cells (data not shown). These data indicate that a concentration of silibinin under $200 \mu \mathrm{M}$ does not exert any cytotoxic effects on HSFs.

Effect of silibinin on type I collagen and MMPs in HSFs. We analyzed the effect of silibinin on the expression of type I collagen, MMP-1 and MMP-2 in cultured fibroblasts. As shown in Fig. 2, silibinin clearly induced the decreased expression of type I collagen and the increased expression of MMP-1 and MMP-2 proteins in a dose-dependent manner; however, the expression of TIMP-1 was not markedly altered. The decreased expression of MMP-1 was clearly observed at $6 \mathrm{~h}$ and the increased expression of MMP-1 was observed at $24 \mathrm{~h}$ following treatment (Fig. 3). The enzymatic activity of MMP-1 was increased in the silibinin-treated cultured fibroblasts, as shown by zymography using casein (data not shown). Furthermore, the markedly decreased promoter activity of type I collagen was confirmed by CAT assay (Fig. 4). We found that silibinin induced the decreased expression of type I collagen, as well as the increased expression of MMP-1 and MMP-2 in the HSFs, demonstrating the anti-fibrotic effects of silibinin on skin. Thus, we focused on the role of silibinin in Smad 2 and Smad3 in cultured HSFs.

Effect of silibinin on Smad2 and Smad3 expression in HSFs. We analyzed the effect of silibinin on the expression of Smad2 and Smad3 in cultured skin fibroblasts. As shown in Fig. 5, 




Figure 2. Silibinin induced the decreased expression of type I collagen and tissue inhibitor of metalloproteinase-1 (TIMP-1), and increased the expression of matrix metalloproteinase (MMP)-1 and MMP-2 in human skin fibroblasts. Expression levels of type I collagen, MMP-1, MMP-2 and TIMP-1 were analyzed by western blot analysis in cultured human skin fibroblasts treated with silibinin at concentrations of $50,100,150$ and $200 \mu \mathrm{M}$ for $48 \mathrm{~h}$.

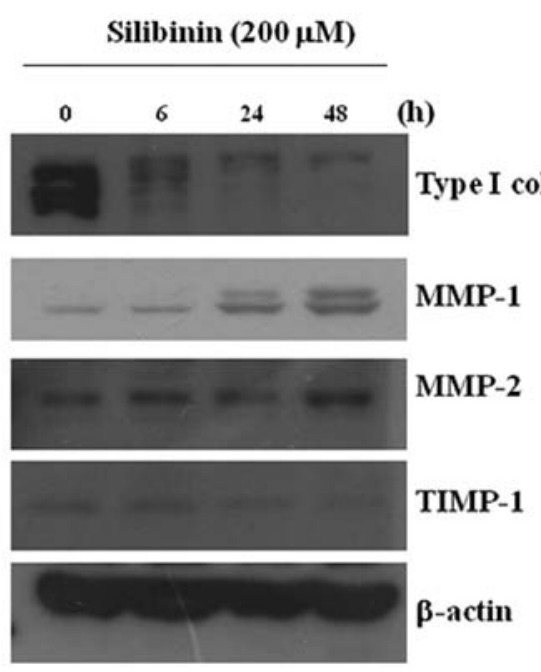

Figure 3. Silibinin induced the decreased expression of type I collagen and tissue inhibitor of metalloproteinase-1 (TIMP-1), and increased the expression of matrix metalloproteinase (MMP)-1 and MMP-2 in human skin fibroblasts. Expression levels of type I collagen, MMP-1, MMP-2 and TIMP-1 were also analyzed by western blot analysis in cultured human skin fibroblasts treated with silibinin at $200 \mu \mathrm{M}$ each for 6,24 and $48 \mathrm{~h}$. Similar results were obtained from 2 different experiments.

at a concentration of $>150 \mu \mathrm{M}$, silibinin did not alter the basal expression level of Smad2, but induced the decreased expression level of Smad3. Of note, silibinin clearly inhibited the TGF- $\beta 1$-induced phosphorylation levels of $\operatorname{Smad} 2$ and Smad3 (Fig. 6).

Effects of silibinin on TGF- $\beta 1$-induced nuclear translocation of Smad2. We further investigated whether silibinin inhibits the nuclear translocation of Smad 2 in TGF- $\beta 1$-treated fibroblasts. The intracellular localization of $\mathrm{p}-\mathrm{Smad} 2$ was examined by immunofluorescence microscopy using antip-Smad2 antibody. At least 100 stained cells were analyzed

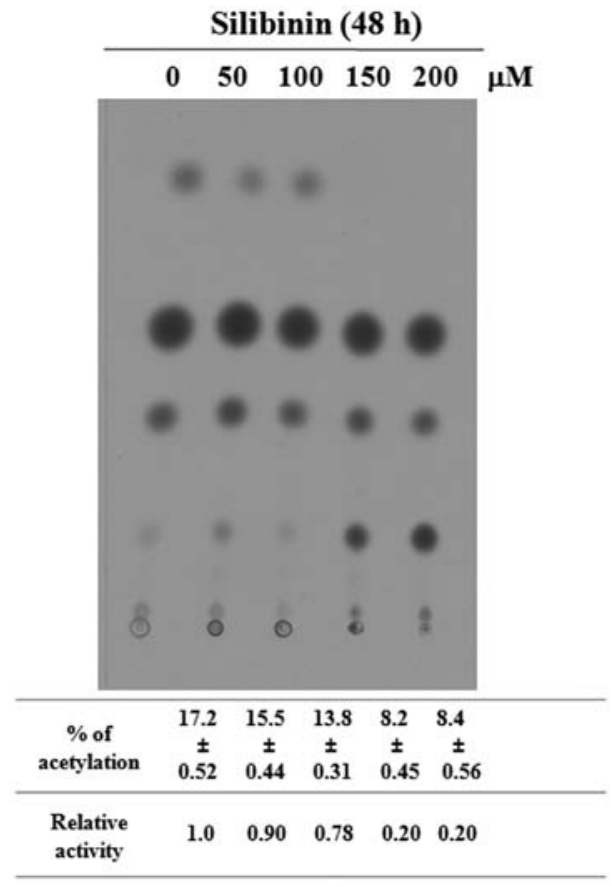

Figure 4. Decreased activity of the $\alpha 1(\mathrm{I})$ procollagen promoter in silibinin-treated fibroblasts. Confluent fibroblasts were transfected with chloramphenicol acetyltransferase (CAT) constructs containing the proximal region of the human $\alpha 1(\mathrm{I})$ procollagen promoter. CAT activity was determined by autoradiography in the acetylated and unacetylated forms of $\left[{ }^{14} \mathrm{C}\right]$ chloramphenicol. Similar results were obtained from 2 different experiments.

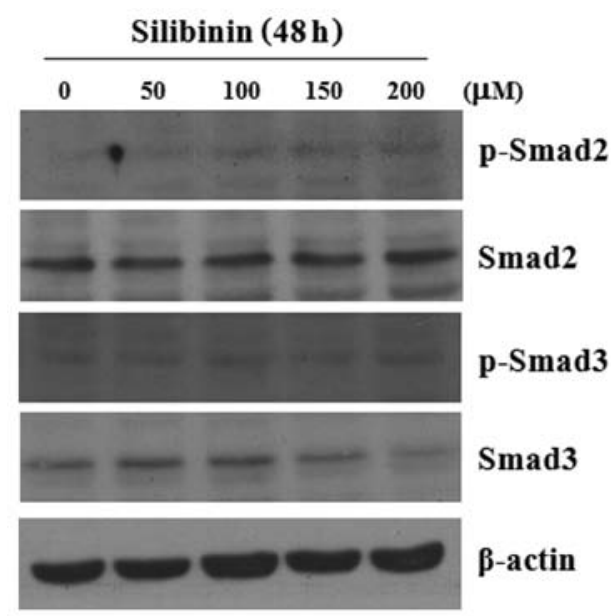

Figure 5. Effect of silibinin on the expression of Smad proteins. Cells were treated with various concentrations of silibinin for $48 \mathrm{~h}$. Whole cell lysates were prepared and used for western blot analysis with respective antibodies. The basal expression levels of Smad proteins were not markedly altered by silibinin treatment. Similar results were obtained from 2 different experiments.

per sample. As shown in Fig. 7, Smad 2 was scarcely phosphorylated in the absence of exogenous TGF- $\beta 1$. The majority of Smad2 proteins that were phosphorylated at the C-terminal region following TGF- $\beta 1$ treatment translocated to the nuclei. Treatment with silibinin $(200 \mu \mathrm{M})$ interrupted the TGF- $\beta 1$ mediated nuclear translocation of $\mathrm{p}-\mathrm{Smad} 2$ in the cells. The nuclear translocation of p-Smad3 was also attenuated by silibinin treatment in the fibroblasts (data not shown). 


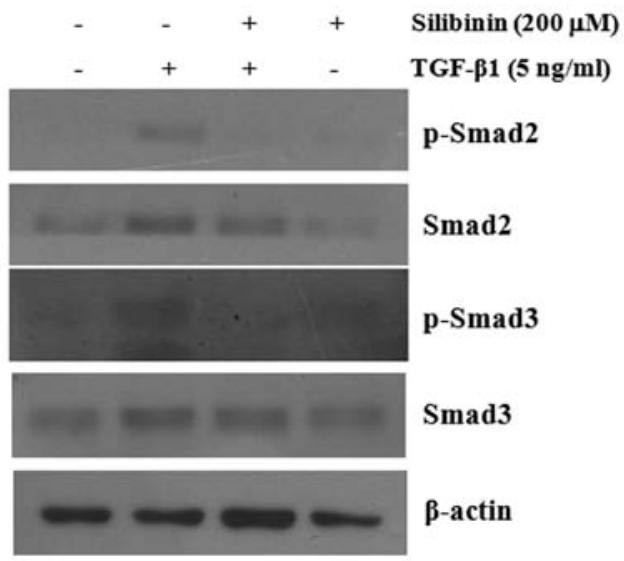

Figure 6. Inhibition of TGF- $\beta 1$-induced phosphorylation of Smad3 and Smad2 in human skin fibroblasts by treatment with silibinin. Cells were treated with TGF- $\beta 1(5 \mathrm{ng} / \mathrm{ml})$ or silibinin $(200 \mu \mathrm{M})$ and co-treated with TGF- $\beta 1$ and silibinin for $6 \mathrm{~h}$. Whole cell lysates were prepared and used for western blot analysis with respective antibodies. Similar results were obtained from 2 different experiments.

\section{Discussion}

The investigation of the molecular mechanisms underlying fibrosis or hypertrophic scar formation has attracted considerable attention in recent years. It has been widely accepted that the dysregulation of the TGF- $\beta /$ Smad pathway plays a key role in hypertrophic or keloid scar formation in human skin tissues. A number of studies have clearly demonstrated that the increased expression of TGF- $\beta$ receptors (types I and II) and the increased phosphorylation of Smad3 in keloid fibroblasts compared to normal HSFs, as well as the suppression of the TGF- $\beta 1 /$ Smad pathway by certain chemicals such as curcumin, may exert chemopreventive effects, thus preventing keloid formation (7-9).

In the current study, we demonstrated that silibinin induced the decreased expression of type I collagen at both the protein and mRNA levels in cultured skin fibroblasts. In addition, the silibinin-induced downregulation of type I collagen expression was partly mediated by the inhibition of the phosphorylation and nuclear translocation of Smad2 and Smad3. In accordance with our findings, silibinin has been shown to attenuate cardiac hypertrophy and fibrosis by blocking epidermal growth factor receptor (EGFR)-dependent signaling, as well as the nuclear factor- $\mathrm{\kappa B}(\mathrm{NF}-\mathrm{\kappa B})$ and TGF- $\beta 1 /$ Smad signaling pathways (10). These findings suggest that silibinin may be an effective therapeutic candidate against hypertrophic or keloid scarring through the downregulation of type I collagen expression.

The phosphorylation and nuclear translocation of Smad2, Smad3 with Smad4 in response to TGF- $\beta 1$ stimulation are critical for the activation of the TGF- $\beta 1 /$ Smad signaling pathway (11-13). TGF- $\beta 1$ induces a complex formation between p-Smad 2 and p-Smad 3 at the C-terminal and linker region with Smad4. The Smad2/3/4 complex translocates to the nucleus to regulate the expression of target genes, such as type I collagen. Namely, TGF- $\beta$-stimulated $\alpha 2(\mathrm{I})$-collagen expression occurs via the cooperation between Smad3 and Smad4, Sp1, CBP/ p300 and Egr-1 (14-16). Our results demonstrated that silibinin attenuated the nuclear translocation of Smad2 and Smad3, as well as the inhibition of the TGF- $\beta$-induced phosphorylation of Smad2 and Smad3. It was observed that the signaling activity of Smad was modulated through phosphorylation and cytosolnucleus translocation. Our data suggest that silibinin may be an effective therapeutic candidate against hypertrophic or keloid scarring through the inhibition of the nuclear translocation and phosphorylation of Smad2 and Smad3.

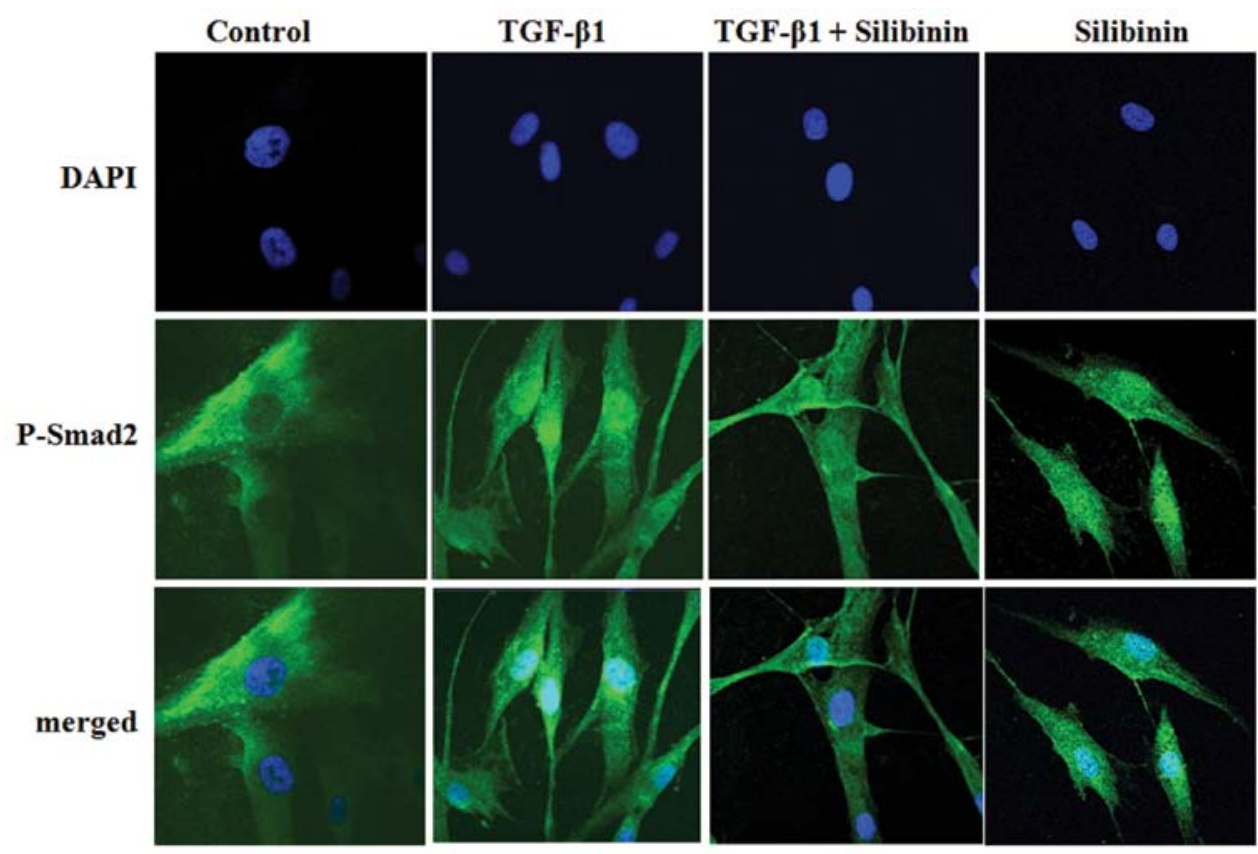

Figure 7. Attenuation of TGF- $\beta 1$-induced nuclear translocation of phosphorylated Smad2 (p-Smad2) in silibinin-treated human skin fibroblasts. Cells were treated with TGF- $\beta 1(5 \mathrm{ng} / \mathrm{ml})$ or silibinin $(200 \mu \mathrm{M})$ and co-treated with TGF- $\beta 1$ and silibinin for $3 \mathrm{~h}$. After the cells were fixed, permeabilized and blocked, they were incubated with each primary antibody followed by fluorescein isothiocyanate-conjugated secondary antibody, and then viewed and photographed under a fluorescence microscope. 
TGF- $\beta$ represses the expression of MMP-1 via Smad 3 and Smad4 with dominant-negative Smad3 or Smad4 mutants abrogating this response (17). If the imbalance of MMP-1 activity occurs in type I collagen synthesis during the wound healing process, the excessive accumulation of the extracellular matrix may result in hypertrophic scarring or keloid formation. In this study, we found that silibinin-treated fibroblasts showed increased MMP-1 and MMP-2 expression levels, as well as a decreased type I collagen expression level. These results suggest that silibinin positively regulates the expression of MMP-1 and MMP-2 through the partial suppression of Smad2/3 activation.

In conclusion, the data from the present study suggest that silibinin has the potential to prevent fibrotic skin changes by inducing the downregulation of type I collagen expression; this effect is is partly mediated by blocking the Smad2/3dependent signaling pathway in HSFs.

\section{Acknowledgements}

This study was supported by a research promotion grant from the Keimyung University Dongsan Medical Center in 2012.

\section{References}

1. Ramasamy K and Agarwal R: Multitargeted therapy of cancer by silymarin. Cancer Lett 269: 352-362, 2008.

2. Muriel P, Moreno MG, Hernández Mdel C, Chávez E and Alcantar LK: Resolution of liver fibrosis in chronic CCl4 administration in the rat after discontinuation of treatment: effect of silymarin, silibinin, colchicine and trimethylcolchicinic acid Basic Clin Pharmacol Toxicol 96: 375-380, 2005.

3. Singh RP, Dhanalakshmi S, Agarwal C and Agarwal R: Silibinin strongly inhibits growth and survival of human endothelial cells via cell cycle arrest and downregulation of survivin, Akt and NF-kappaB: implications for angioprevention and antiangiogenic therapy. Oncogene 24: 1188-1202, 2005.

4. Rahimi RA and Leof EB: TGF-beta signaling: a tale of two responses. J Cell Biochem 102: 593-608, 2007.

5. Xie JL, Qi SH, Pan S, Xu YB, Li TZ, Liu XS and Liu P: Expression of Smad protein by normal skin fibroblasts and hypertrophic scar fibroblasts in response to transforming growth factor beta1. Dermatol Surg 34: 1216-1225, 2008.
6. Zi Z, Chapnick DA and Liu X: Dynamics of TGF- $\beta /$ Smad signaling. FEBS Lett 586: 1921-1928, 2012.

7. Hsu YC, Chen MJ, Yu YM, Ko SY and Chang CC: Suppression of TGF- $\beta 1 / \mathrm{SMAD}$ pathway and extracellular matrix production in primary keloid fibroblasts by curcuminoids: its potential therapeutic use in the chemoprevention of keloid. Arch Dermatol Res 302: 717-724, 2010.

8. He S, Liu X, Yang Y, Huang W, Xu S, Yang S, Zhang X and Roberts MS: Mechanisms of transforming growth factor beta(1)/Smad signalling mediated by mitogen-activated protein kinase pathways in keloid fibroblasts. Br J Dermatol 162: 538-546, 2010.

9. Chin GS, Liu W, Peled Z, Lee TY, Steinbrech DS, Hsu M and Longaker MT: Differential expression of transforming growth factor-beta receptors I and II and activation of Smad 3 in keloid fibroblasts. Plast Reconstr Surg 108: 423-429, 2001.

10. Ai W, Zhang Y, Tang QZ, Yan L, Bian ZY, Liu C, Huang H, Bai X, Yin L and Li H: Silibinin attenuates cardiac hypertrophy and fibrosis through blocking EGFR-dependent signaling. J Cell Biochem 110: 1111-1122, 2010.

11. Shi Y and Massagué J: Mechanisms of TGF-beta signaling from cell membrane to the nucleus. Cell 113: 685-700, 2003.

12. Moustakas A, Pardali K, Gaal A and Heldin CH: Mechanisms of TGF-beta signaling in regulation of cell growth and differentiation. Immunol Lett 82: 85-91, 2002.

13. Chen HB, Rud JG, Lin K and Xu L: Nuclear targeting of transforming growth factor-beta-activated Smad complexes. J Biol Chem 280: 21329-21336, 2005.

14. Poncelet AC and Schnaper HW: Sp1 and Smad proteins cooperate to mediate transforming growth factor-beta 1-induced alpha 2(I) collagen expression in human glomerular mesangial cells. J Biol Chem 276: 6983-6992, 2001.

15. Ghosh AK, Yuan W, Mori Y and Varga J: Smad-dependent stimulation of type I collagen gene expression in human skin fibroblasts by TGF-beta involves functional cooperation with p300/CBP transcriptional coactivators. Oncogene 19: 3546-3555, 2000.

16. Chen SJ, Ning H, Ishida W, Sodin-Semrl S, Takagawa S, Mori Y and Varga J: The early-immediate gene EGR-1 is induced by transforming growth factor-beta and mediates stimulation of collagen gene expression. J Biol Chem 281: 21183-21197, 2006.

17. Yuan W and Varga J: Transforming growth factor-beta repression of matrix metalloproteinase-1 in dermal fibroblasts involves Smad3. J Biol Chem 276: 38502-38510, 2001. 